\title{
PERANCANGAN SISTEM MONITORING KONDISI GEDUNG MENGGUNAKAN KONSEP WIRELESS SENSOR NETWORK
}

\author{
Asep Najmurrokhman ${ }^{1}$, Kusnandar ${ }^{2}$, Bambang HSR Wibowo ${ }^{3}$ dan Andef Abdillah ${ }^{4}$ \\ ${ }^{1,2,3,4}$ Jurusan Teknik Elektro, Universitas Jenderal Achmad Yani \\ Jl. Trs Jenderal Sudirman PO Box 148 Cimahi 40533 \\ Email: asepnajmu@yahoo.com
}

\begin{abstract}
ABSTRAK
Era globalisasi dan simbol negara yang perekonomiannya tumbuh dicirikan salahsatunya dengan pembangunan gedung bertingkat. Gedung tersebut difungsikan sebagai mall, perkantoran, apartemen, atau institusi negara dan swasta. Salahsatu yang menjamin aspek keselamatan dan keamanan gedung adalah tersedianya sistem peringatan dini terhadap bahaya atau bencana yang timbul, seperti kebakaran dan gempa bumi. Makalah ini memaparkan tentang prototipe sistem monitoring kondisi gedung bertingkat dari aspek potensi munculnya kebakaran dan peringatan terhadap terjadinya gempa bumi. Sistem yang dibangun menggunakan prinsip wireless sensor network dengan modul utamanya prosesor Xbee keluaran Digi Internasional yang dapat mengolah data dan mentransmisikan secara wireless. Dalam prototipe tersebut, tiga tipe sensor digunakan untuk mendeteksi adanya asap, api, dan getaran. Data sensor diolah oleh modul Xbee transmitter dan dikirimkan secara wireless kepada subsistem penerima modul Xbee receiver. Selanjutnya, data yang diterima oleh modul tersebut diproses dan ditampilkan dalam bentuk data numerik melalui tampilan di layar laptop. Hasil pengujian memperlihatkan bahwa sistem pengiriman dan penerimaan data sensor berjalan dengan baik. Namun demikian, komunikasi data secara wireless sangat tergantung kepada topologi dan bentuk gedung.
\end{abstract}

Kata kunci: wireless sensor network, modul Xbee, monitoring gedung, sensor api, sensor asap, sensor getaran

\section{PENDAHULUAN}

Era globalisasi dan simbol negara yang perekonomiannya maju dicirikan salahsatunya dengan pembangunan gedung bertingkat. Gedung bertingkat berfungsi sebagai pusat perbelanjaan, perkantoran, apartemen, atau institusi negara. Faktor keamanan dalam gedung bertingkat menjadi hal utama dalam menjamin keselamatan pengguna gedung. Untuk menjamin keselamatan pengguna gedung, sistem peringatan dini (early warning system) terhadap bahaya atau bencana yang terjadi harus diterapkan bersamaan dengan proses mitigasi dan evakuasi korban dalam bencana tersebut. Sistem peringatan dini memainkan peranan penting dalam upaya meminimalisir jumlah korban dan tingkat kerusakan yang lebih parah. Menurut Quansah et al. (2010), sistem peringatan dini menyangkut tentang pendekatan dan penggunaan teknologi dalam bidang perancangan sensor untuk pengumpulan data dari berbagai sumber agar diperoleh data atau kondisi secara real time. Sistem peringatan dini juga mencakup teknik menyajikan informasi agar diperoleh respon efektif terhadap informasi tersebut. Dalam kaitan dengan keamanan gedung bertingkat, ada dua potensi bahaya atau bencana yang mengancam keselamatan pengguna gedung yaitu kebakaran dan gempa bumi. Potensi kebakaran timbul akibat kelalaian manusia dalam menggunakan fasilitas yang berhubungan dengan api atau terjadinya korsluiting pada instalasi listrik akibat usia jaringan listrik yang sudah tua atau karena dirusak oleh hewan pengerat seperti tikus. Sementara itu, bencana gempa bumi selalu mengancam wilayah di Indonesia karena secara geologis, wilayah Indonesia dilalui oleh dua jalur pegunungan muda dunia yaitu Pegunungan Mediterania di sebelah barat dan Pegunungan 
Sirkum Pasifik di sebelah timur dan terletak di tiga daerah dangkalan, yaitu Dangkalan Sunda, Dangkalan Sahul, dan Laut Pertengahan Australia Asiatis. Adanya dua jalur pegunungan tersebut menyebabkan Indonesia banyak memiliki gunung api yang aktif dan rawan terjadinya gempa bumi. Dengan demikian, sistem peringatan dini terhadap bahaya kebakaran dan potensi gempa bumi terhadap keamanan pengguna gedung merupakan bagian yang penting dalam perencanaan gedung bertingkat.

Setiap pembangunan gedung di Indonesia harus memenuhi standar dalam bidang konstruksi dan bangunan yang ditetapkan oleh Badan Standardisasi Nasional (BSN). Salahsatu standar yang harus dipenuhi adalah standar perlindungan terhadap bahaya kebakaran pada bangunan gedung, antara lain terdiri dari tata cara perencanaan, pemasangan, dan pengujian sistem deteksi dan alarm kebakaran untuk pencegahan bahaya kebakaran [Adhipradana dkk. (2009)]. Hal tersebut menunjukkan bahwa sistem deteksi dan peringatan dini terhadap bahaya pada bangunan gedung adalah hal yang sangat kritis dan harus disiapkan sebagai bagian dari perencanaan bangunan. Sementara itu, Siregar dkk. (2015) melaporkan bahwa masih banyak gedung bertingkat yang belum memenuhi standar bidang konstruksi dan bangunan yang telah ditetapkan oleh Badan Standarisasi Nasional (BSN). Hal ini berkaitan dengan kurangnya kesadaran akan pentingnya kesehatan dan keselamatan kerja (K3). Sering timbul anggapan bahwa K3 merupakan pemborosan pengeluaran biaya yang harus dipenuhi pada sebuah gedung bertingkat. Prosedur K3 di gedung bertingkat sangat penting karena gedung bertingkat memiliki risiko yang tidak dapat diprediksi, misalnya pada saat terjadi gempa atau kebakaran. Untuk meningkatkan faktor keamanan gedung bertingkat dari bahaya dan bencana, sebuah sistem peringatan dini harus disiapkan oleh pengelola gedung. Sistem tersebut berfungsi mengolah data atau informasi berupa kondisi yang terjadi setiap saat di seluruh area gedung tersebut. Data atau informasi dapat diperoleh secara manual melalui petugas yang disiapkan di setiap area. Seiring dengan perkembangan teknologi, untuk meningkatkan keefektifan pengiriman data dan otomatisasi dalam pengolahan datanya, informasi dapat diperoleh dari penggunaan sensor-sensor yang bersesuaian, misalnya sensor suhu, kamera, sensor asap, dan sensor getaran.

Penggunaan sensor di gedung bertingkat berkorelasi dengan jumlah jalur transmisi yang harus diinstalasi untuk mengirimkan data atau informasi yang dideteksi oleh sensor. Semakin banyak area yang harus dipasang sensor, maka semakin banyak dan rumit jalur transmisi yang harus dibuat. Hal tersebut menambah kesulitan tersendiri dalam hal pemeliharaan dan perawatan serta deteksi kesalahan informasi yang dikirim. Dewasa ini, implementasi sensor dalam jumlah banyak dan untuk aplikasi mitigasi bencana mengarah kepada penggunaan konsep wireless sensor network (WSN) [Kaur et al. (2012)]. Dengan konsep WSN, transmisi data dari sensor ke bagian lain melalui saluran udara langsung (wireless), sehingga mereduksi secara drastis penggunaan kabel dalam implementasi sistemnya. Beberapa peneliti telah mengungkapkan vitalnya implementasi WSN dalam menangani bencana [Ahmad et al. (2011), Dawood et al. (2013), Seal et al. (2012), Yawut \& Kilaso (2011)]. Ahmad et al. (2011) melaporkan bahwa WSN dapat diterapkan secara efisien dan kompak dalam suatu skenario infrastruktur ad hoc saat terjadi bencana. Dawood et al. (2013) mengkaji kinerja WSN dalam manajemen penanggulangan bencana diukur dalam beberapa metrik seperti efisiensi energi, location awareness, dan network life time. Sementara itu, Seal et al. (2012) merancang arsitektur WSN dalam mendukung sistem peringatan dini banjir, sedangkan Yawut \& Kilaso (2011) mengusulkan konfigurasi WSN dalam menangani bencana dan prediksi cuaca. 
Dalam konteks sistem pengamanan pada bangunan atau gedung, beberapa peneliti telah melaporkan penggunaan sensor dalam mendeteksi besaran yang diukur di area gedung, seperti sensor suhu [Sugiarto (2010)] dan sensor asap [Haryoko (2009)] atau keduanya [Usuman \& Ardhi (2010)]. Data yang diperoleh dari sensor tersebut kemudian dikirimkan melalui protokol komunikasi yang disebut dengan Zigbee untuk diproses lebih lanjut. ZigBee adalah standar jaringan mesh nirkabel dengan daya rendah dan biaya yang murah [Arkan \& Zaini (2014)]. Dengan biaya yang murah memungkinkan teknologi ini banyak digunakan sebagai pengendali jaringan nirkabel dan aplikasi pemantauan. Selain itu, penggunaannya dengan daya yang rendah membuatnya dapat bertahan lama bahkan dengan baterai berukuran lebih kecil. Dalam konteks topologi jaringan, jaringan mesh memberikan realibilitas yang tinggi serta jangkauan yang lebih luas. Beberapa vendor sudah mengembangkan perangkatnya untuk mendukung aplikasi WSN dengan protokol Zigbee. Salahsatu yang secara luas dipakai dan juga digunakan dalam penelitian yang dilaporkan dalam makalah ini adalah Xbee. Xbee adalah merk dagang dari Digi International untuk modul komunikasi radio. Modul ini menggunakan standar IEEE 802.15.42003 yang dirancang untuk komunikasi point-to-point dan topologi star atau mesh dengan kecepatan transmisi data $250 \mathrm{kbit} / \mathrm{s}$. Modul Xbee yang digunakan terbagi menjadi dua yaitu modul Xbee transmitter dan Xbee receiver. Modul Xbee transmitter akan dimanfaatkan untuk mentransmisikan data yang diperoleh dari sensor suhu, sensor asap, dan sensor getaran, sedangkan Xbee receiver berfungsi menerima data yang dipancarkan oleh Xbee transmitter. Sensor suhu yang digunakan adalah IC LM35, sedangkan sensor asapnya menggunakan AF-30. Sementara itu, sensor untuk mendeteksi getaran akan memanfaatkan sensor getar piezoelektrik. Dalam prototipe ini juga akan dibangun sebuah display (tampilan) yang terpasang pada ruang kendali yang memuat informasi besar suhu, intensitas asap, dan getaran di ruang tempat diletakkan sensor-sensor tersebut.

\section{PERANCANGAN SISTEM}

Prototipe sistem keamanan gedung bertingkat yang dibuat berupa konfigurasi tiga sensor yang diolah secara paralel oleh modul Xbee Transmitter dan dikirimkan melalui udara tanpa kabel (wireless) ke modul Xbee Receiver untuk diolah dan ditampilkan datanya dalam display (monitor komputer). Tiga sinyal yang dideteksi adalah data suhu, kondisi asap, dan getaran yang merepresentasikan kondisi ada tidaknya kebakaran, asap rokok, atau potensi getaran akibat gempa bumi. Dalam prototipe ini, dua modul Xbee Transmitter masing-masing disimpan dalam ruang yang berbeda, sedangkan modul Xbee Receiver disimpan di ruang lain yang berfungsi sebagai ruang kendali (control room). Dalam ruang kendali tersebut, sebuah display akan menampilkan informasi tentang keadaan suhu, asap, dan getaran di setiap ruang serta warning system yang memberi tahu jika terjadi kondisi anomali atau adanya potensi bahaya dalam ruangan tersebut. Konfigurasi sistem keseluruhan merealisasikan konsep wireless sensor network artinya koneksi antar modul sensor dengan penerima melalui udara tanpa kabel sehingga modul sensor dapat dipindahkan dengan mudah, dapat mengatasi halangan yang ada dalam ruangan, dan jarak antara modul transmitter dan receiver dapat diatur sesuai dengan spesifikasi teknis yang masih dapat ditangani oleh komponen tersebut. Diagram blok sistem tersebut diperlihatkan pada Gambar 1. 


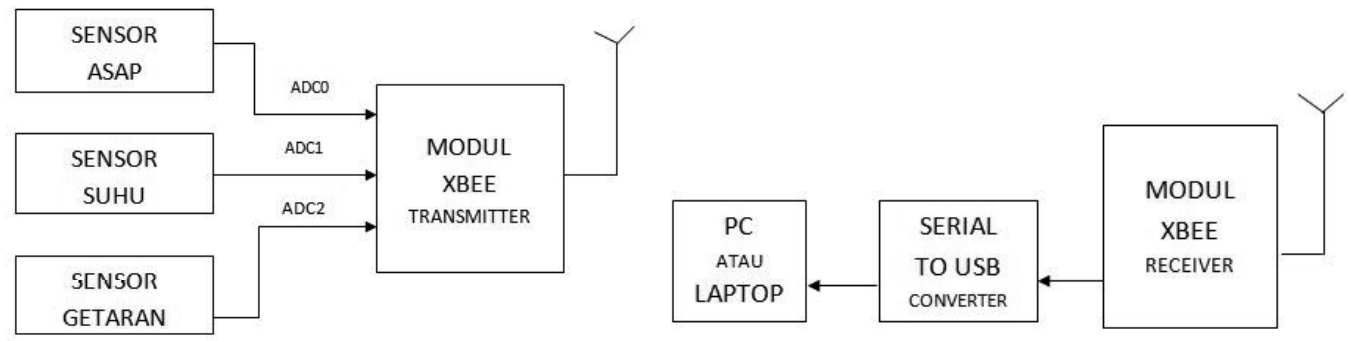

Gambar 1. Diagram blok sistem

Berdasarkan Gambar 1, komponen utama yang menyusun sistem yang dibangun terdiri atas sensor asap, sensor suhu, sensor getaran, modul Xbee transmitter, modul Xbee receiver, dan laptop. Realisasi sistemnya diberikan dalam Gambar 2.

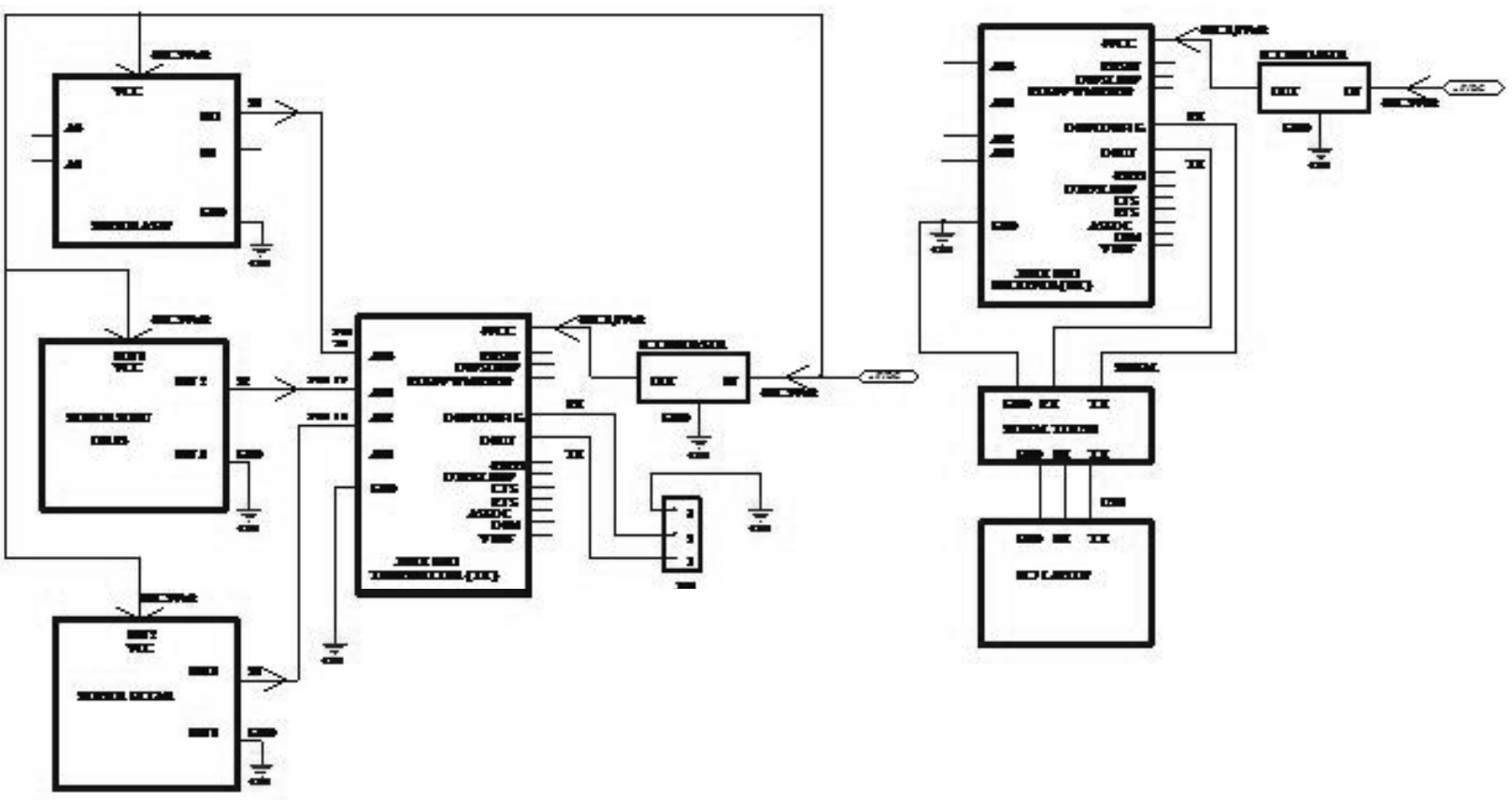

Gambar 2. Realisasi sistem

Komponen utama yang menyusun sistem yang dibangun terdiri atas sensor asap, sensor suhu, sensor getaran, modul Xbee transmitter, modul Xbee receiver, dan laptop. Sensor asap menggunakan IC MQ-5 yang terdiri dari 2 elektroda dan ditengahnya ada sebuah pemanas, dimana pemanas dan salahsatu elektroda diberi tegangan 5 Volt. Apabila ada asap yang masuk ke dalam sensor tersebut akan menyebabkan output dari elektroda akan mengeluarkan tegangan antara $0 \quad 5 \mathrm{~V}$ sesuai kepekatan asap. Output dari sensor asap dikoneksikan ke pin AD0 dari Xbee. Sementara itu, sensor suhu menggunakan IC LM35 yang akan mendeteksi suhu lingkungan dan mengeluarkan tegangan output dengan pertambahan $10 \mathrm{mV}$ setiap kenaikan suhu 1 derajat Celcius. Output dari sensor suhu akan masuk pada AD1 dari XBee. Sensor getaran berupa piezo film vibra dengan sensitivitas $50 \mathrm{mV}$ per gram tekanan digunakan untuk mendeteksi getaran yang terjadi. Apabila sensor yang berupa lempengan tersebut diberi beban pada ujungnya dan mendapat getaran atau guncangan, maka beban tersebut akan menekan sensor tersebut dan menghasilkan tegangan sesuai besar tekanan yang ditimbulkan. Keluaran dari sensor getaran masuk ke port AD2 dari XBee. Ketiga variabel jenis data analog yang keluar dari 
setiap sensor akan diproses dalam waktu yang bersamaan ke pin AD0, AD1, dan AD2 pada modul Xbee transmitter (TX) dengan sistem serial dan data dari ketiga sensor dikirim secara berurutan. Selanjutnya pada modul Xbee receiver (RX) ketiga data yang berbeda variabelnya akan diuraikan dengan teknik memecah data menjadi 3 bagian sesuai urutan data pada saat dikirim, kemudian pada program Delphi akan dimunculkan tiga parameter data yang berbeda sesuai dengan yang dikirim oleh masing-masing sensor tersebut.

Pengiriman tiga jenis data variabel analog yang berbeda dari modul Xbee transmitter (TX) ke modul Xbee receiver (RX) pada jarak tertentu menggunakan teknik transmisi melalui gelombang radio sebagai frekuensi pembawanya. Modul Xbee-Pro 900 bekerja pada frekuensi pembawa sebesar 2,4 Ghz, dengan jangkauan pancar 300 kaki pada daya output $1 \mathrm{~mW}$. Adapun sistem protokol adalah sistem 802.15.4 dengan kecepatan data maksimal $250 \mathrm{kbs}$. Modul Xbee Pro yang digunakan mengkonsumsi arus sebesar $50 \mathrm{~mA}$ dengan tegangan batere maksimum sebesar 3,3Volt. Teknik modulasi yang digunakan dalam komunikasi data adalah Frequency Shift Keying (FSK). Teknik modulasi FSK adalah teknik modulasi yang menyatakan sinyal digital 1 sebagai suatu nilai tegangan dengan frekuensi tertentu (misalnya $\mathrm{f} 1=1200 \mathrm{~Hz}$ ), sementara sinyal digital 0 dinyatakan sebagai suatu nilai tegangan dengan frekuensi tertentu yang berbeda (misalnya $\mathrm{f} 2=2200 \mathrm{~Hz}$ ). Sama seperti modulasi fase, pada modulasi frekuensi yang lebih rumit dapat dilakukan pada beberapa frekuensi sekaligus, sehingga pengiriman data menjadi lebih efisien.

Data yang diterima oleh modul Xbee receiver selanjutnya dikirimkan kepada PC atau Laptop melalui jalur interface atau kabel penghubung serial to USB. Sebuah program aplikasi menggunakan Delphi dibuat untuk menampilkan data dari ketiga sensor yang digunakan. Proses pembacaan tiga data variabel dari sensor dapat diterangkan sebagai berikut :

a. Data serial yang masuk ke laptop atau PC dibaca oleh perangkat lunak yang dibuat untuk dipisahkan antara header dan data sensornya.

b. Data dari masing-masing sensor akan dikonversi ke nilai sebenarnya sesuai dengan rumus konversi dari masing-masing sensor.

c. Nilai hasil konversi akan ditampilkan di display seven segment pada program aplikasi yang dibuat.

Tampilan di layar laptop atau PC diperlihatkan pada Gambar 3.

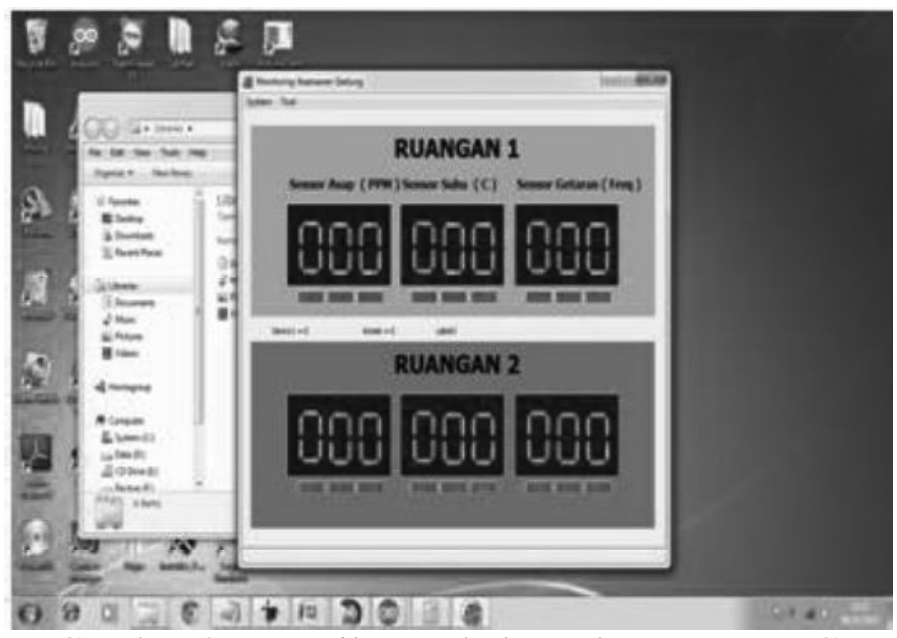

Gambar 3. Tampilan pada layar laptop atau PC 


\section{HASIL PENGUJIAN DAN PEMBAHASAN}

Dalam prototipe sistem monitoring kondisi gedung ini, simulasi sistemnya dilakukan dengan menempatkan dua modul XBee transmitter yang menggambarkan dua lokasi berbeda pada gedung tersebut. Selanjutnya, kondisi gedung yang diberikan oleh tiga data sensor dibedakan menjadi low, medium, dan high tergantung dari nilai masing-masing data yang dideteksi oleh setiap sensor. Data dari sensor asap yang menggambarkan terjadinya kebakaran dipisahkan menjadi tiga kondisi yang berbeda sesuai dengan kepekatan asap. Sementara itu, dari dari sensor suhu dibedakan menjadi tiga kondisi yaitu low untuk suhu di bawah $40^{\circ} \mathrm{C}$, medium untuk suhu antara $40^{\circ} \mathrm{C}$ sampai $55^{\circ} \mathrm{C}$, dan high untuk suhu di atas $55^{\circ} \mathrm{C}$. Hasil pengujian untuk beberapa kondisi yang terjadi diperlihatkan pada Gambar 4.
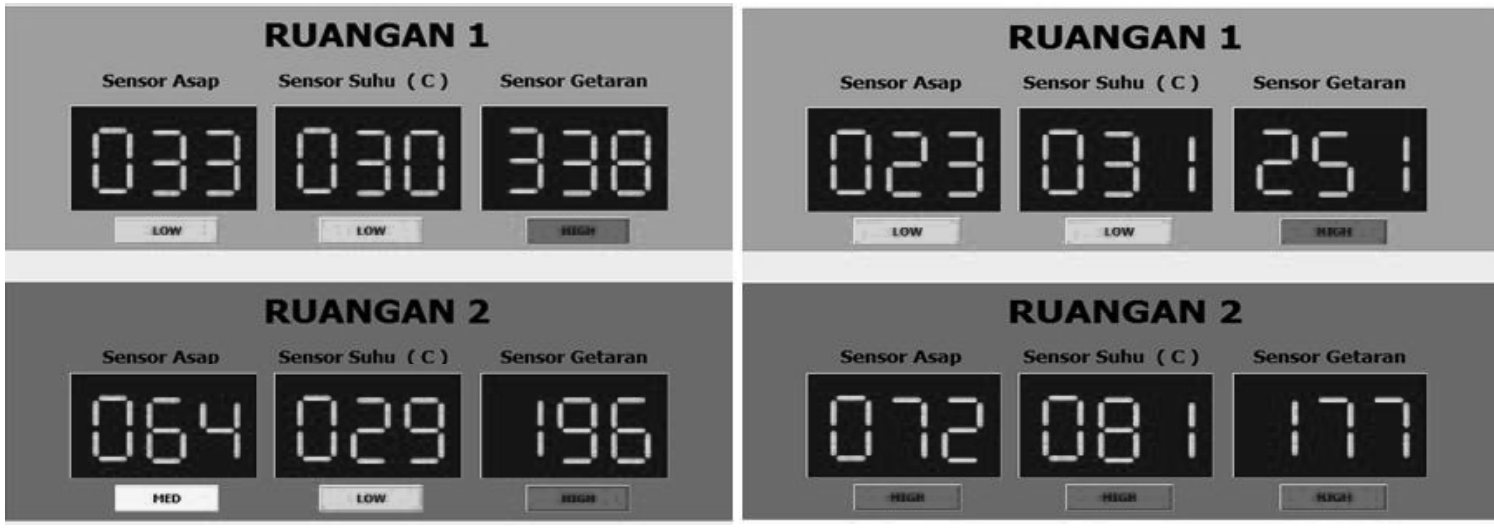

Gambar 4. Tampilan pada layar laptop atau PC untuk beberapa kondisi

Karena transmisi data yang dikirim secara wireless, maka kondisi hubungan antara modul Xbee transmitter dan XBee receiver sangat berpengaruh dalam pembacaan datanya. Hasil pengujian terhadap jarak pancar antara dua modul tersebut di lingkungan dalam ruangan dan luar ruangan diberikan dalam Tabel 1 dan Tabel 2.

Tabel 1. Hubungan antara jarak pancar dengan delay dalam kondisi di dalam ruangan

\begin{tabular}{cc}
\hline Jarak $(\mathrm{m})$ & Delay $(\mathrm{s})$ \\
\hline 10 & 0 \\
\hline 20 & 0 \\
\hline 50 & $\operatorname{Max} 20$ \\
\hline 60 & $\operatorname{Max} 21$ \\
\hline 70 & $\operatorname{Max} 22$ \\
\hline 80 & $\operatorname{Max} 25$ \\
\hline 90 & $\operatorname{Max} 35$ \\
\hline$>100$ & $\infty$ \\
\hline
\end{tabular}


Seminar Nasional Teknologi dan Sains (SNTS) II 2016

Peran Perguruan Tinggi dalam Pembangunan Berkelanjutan Untuk

Kesejahteraan Masyarakat

Jakarta, 23-24 Agustus 2016

Tabel 1. Hubungan antara jarak pancar dengan delay dalam kondisi di luar ruangan (line of sight)

\begin{tabular}{cc}
\hline Jarak $(\mathrm{m})$ & Delay $(\mathrm{s})$ \\
\hline 10 & 0 \\
\hline 30 & 0 \\
\hline 60 & 0 \\
\hline 70 & $\operatorname{Max} 2$ \\
\hline 80 & $\operatorname{Max} 5$ \\
\hline 100 & Max 10 \\
\hline$>105$ & $\infty$ \\
\hline
\end{tabular}

Berdasarkan pengujian yang dilakukan dapat diketahui bahwa komunikasi data antar modul Xbee di luar ruangan (kondisi line of sight) dapat terjadi sampai jarak maksimum 105 meter, sedangkan di dalam ruangan dapat terjadi pada jarak maksimum 100 meter. Ketika dilakukan pengujian yang berada di area dalam ruangan, untuk jarak $1 \mathrm{~s} / \mathrm{d} 49$ meter berlangsung dengan baik. Namun pada jarak 50 meter sudah mengalami delay selama maksimal 20 detik dan pada jarak 100 meter data yang dikirim gagal, sehingga mengakibatkan terputusnya komunikasi antara Xbee TX dengan Xbee RX. Hal tersebut dipengaruhi oleh defleksi sinyal input dan faktor kontur daerah tersebut yang mempengaruhi kinerja transmisi data pada sistem ini.

\section{KESIMPULAN}

Makalah ini telah menguraikan prototipe sistem monitoring kondisi gedung menggunakan wireless sensor network dengan modul Xbee sebagai komponen utamanya. Monitoring kondisi gedung direpresentasikan dengan data kepekatan asap, suhu, dan getaran yang dideteksi oleh masing-masing sensor di dua ruangan yang berbeda. Sebuah program aplikasi yang dibangun dengan perangkat lunak Delphi dibuat di sisi penerima untuk memperlihatkan kondisi gedung tersebut. Transmisi data antara modul Xbee transmitter dan modul Xbee receiver dipengaruhi oleh kondisi topologi dari area gedung tersebut. Berdasarkan pengujian, semakin jauh jarak antara pemancar dan penerima modul Xbee semakin besar waktu tunda pembacaan data di sisi penerima. Jarak maksimum antara pemancar dan penerima dari modul Xbee agar komunikasi data masih dapat berjalan dengan baik di area tertutup dalam ruangan adalah $100 \mathrm{~m}$, sedangkan jarak maksimum di antara kedua modul tersebut di daerah terbuka adalah $105 \mathrm{~m}$.

\section{DAFTAR PUSTAKA}

Adhipradana, B., Rahman, A., Dewi, R.S. (2009). Perancangan Prototype Direct Notification System Untuk Meminimasi Pre-Evacuation Time Pada Proses Evakuasi Gedung Dengan Menggunakan Teknologi Short Messaging Service (SMS) Gateway (Studi Kasus: PT Otsuka Indonesia)", Tugas Akhir Jurusan Teknik Industri ITS Surabaya.

Ahmad, N., Riaz, N., Hussain, M. (2011). "Ad hoc wireless Sensor Network Architecture for Disaster Survivor Detection”. International Journal of Advanced Science and Technology, Vol. 34, September 2011, pp. 9-16.

Arkan, F. dan Zaini. (2014). "Aplikasi Teknologi Zigbee Pada Sistem Detektor Kebakaran Pada Rumah Susun Jurnal Teknik Elektro ITP, Volume. 3, No. 1, Januari 2014, hlm. 11-18. 
Seminar Nasional Teknologi dan Sains (SNTS) II 2016

Peran Perguruan Tinggi dalam Pembangunan Berkelanjutan Untuk

Kesejahteraan Masyarakat

Jakarta, 23-24 Agustus 2016

Dawood, M.S., Suganya, J., Devi, R.K., Athisha, G. (2013). "A Review on Wireless Sensor Network Protocol for Disaster Management". Intern. Journal of Computer Applications Technology and Research, Volume 2, Issue 2, 141 - 146.

Haryoko, S. (2009). "Karakteristik Sensor AF-30 pada Rangkaian Detektor Asap". Jurnal MEDIA ELEKTRIK, Vol. 4, No. 1, Juni 2009, hlm. 1-9.

Kaur, H., Sawhney, R.S., Komal, N. (2012). "Wireless Sensor Networks for Disaster Management". International Journal of Advanced Research in Computer Engineering \& Technology, Volume 1, Issue 5, July 2012, pp. 129-134.

Quansah, J., Engel, B., Rochon, G.L. (2010). "Early Warning Systems: A Review". The Journal of Terrestrial Observation, Vol. 2, No. 2, 2010, pp. 24-44.

Saoji, A. and Lambhate, P.D. (2014). "Trusted Clustering Based Event Detection for Disaster Management in Wireless Sensor Network". International Journal of Computer Science and Information Technologies, Vol. 5, No. 4, 2014, 5179-5181.

Seal, V., Raha, A., Maity, S., Mitra, S.K., Mukherjee, A., Naskar, M.K. (2014). “A Simple Flood Forecasting Scheme Using Wireless Sensor Networks". International Journal of Ad hoc, Sensor \& Ubiquitous Computing (IJASUC) Vol.3, No.1, February 2012, pp. 45-60.

Siregar, E.S., Yuniar, Desrianty, A. (2015). "Usulan Perancangan Jalur Evakuasi Menggunakan Algoritma Djikstra". Jurnal Reka Integra, Vol. 03, No. 01, Januari 2015, hlm. 73-84.

Sugiarto, B. (2010). "Perancangan Sistem Pengendalian Suhu pada Gedung Bertingkat dengan Teknologi Wireless Sensor Network". Jurnal Ilmiah Teknik Mesin Cakram, Vol. 4, No.1, April 2010, hlm.62-68.

Usuman, I. dan Ardhi, H. (2010). "Sistem Pendeteksi Suhu Dan Asap Pada Ruangan Tertutup Memanfaatkan Sensor LM35 dan Sensor AF30". Jurnal Berkala Fisika, Vol 13., No.2, Edisi khusus April 2010, hlm. B1-B6.

Yawut, C. and Kilaso, S. (2011). "A Wireless Sensor Network for Weather and Disaster Alarm Systems International Conference on Information and Electronics Engineering, Singapore, pp. 155-159. 